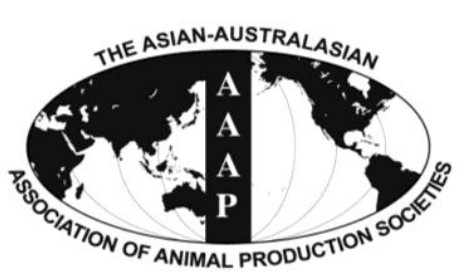

Open Access

Asian Australas. J. Anim. Sci.

Vol. 28, No. 8 : 1105-1115 August 2015

http://dx.doi.org/10.5713/ajas.14.0937

www.ajas.info

pISSN 1011-2367 elSSN 1976-5517

\title{
Influence of Restricted Grazing Time Systems on Productive Performance and Fatty Acid Composition of Longissimus dorsi in Growing Lambs
}

\author{
Zhenzhen Wang ${ }^{1, a}$, Yong Chen ${ }^{1,2, a}$, Hailing Luo ${ }^{1, *}$, Xueliang Liu ${ }^{1}$, and Kun Liu ${ }^{1}$ \\ ${ }^{1}$ State Key Laboratory of Animal Nutrition, China Agricultural University, Beijing 100193, China
}

\begin{abstract}
Fifty 3-month-old male Tan lambs (similar in body weight) were divided into 5 groups to investigate the effects of different restricted pasture grazing times and indoor supplementation on the productive performances and fatty acid composition of the intramuscular fat in growing lambs. The lambs grazed for different periods of time $(12 \mathrm{~h} / \mathrm{d}, 8 \mathrm{~h} / \mathrm{d}, 4 \mathrm{~h} / \mathrm{d}, 2 \mathrm{~h} / \mathrm{d}$, and $0 \mathrm{~h})$ and received various amounts of supplementary feedings during the 120-day trial. Pasture dry matter intake (DMI), total DMI, average daily gains and the live body weights of the lambs were measured during the experiment. The animals were slaughtered at the end of the study, their carcass traits were measured, and their longissimus dorsi muscles were sampled to analyze the intramuscular fat (IMF) content and fatty acid profiles. The results indicated that the different durations of grazing and supplementary feedings affected the animal performances and the composition of fatty acids. Grazing for $8 \mathrm{~h} / \mathrm{d}$ or $2 \mathrm{~h} / \mathrm{d}$ with the corresponding supplementary concentrate resulted in lambs with higher body weights, carcass weights and IMF contents. Lambs with longer grazing times and less concentrate accumulated more healthy fatty acids such as conjugated linoleic acid and $n-3$ polyunsaturated fatty acid and had higher $n-3 / n-6$ ratios. Overall, a grazing allowance of $8 \mathrm{~h} / \mathrm{d}$ and the corresponding concentrate was recommended to maintain a high quantity and quality of lamb meat. (Key Words: Grazing Time Allowance, Animal Performance, Fatty Acid Profile, Tan Lamb)
\end{abstract}

\section{INTRODUCTION}

Currently, consumers are eager to obtain high quality and healthy lamb meat. Attention has been given to lipids that contain different types of fatty acids, some of which are essential and healthy for humans whereas others are not. It is well known that lamb meat that contains more $n-3$ polyunsaturated fatty acids (PUFAs) and conjugated linoleic acids (CLAs) but less saturated fatty acids (SFA) and $n-6$ PUFA is more desirable. $n-3$ PUFA is famous for its protective and modifying effects on a variety of diseases such as multiple sclerosis, major depression, atherosclerosis,

\footnotetext{
* Corresponding Author: Hailing Luo. Tel: +86-10-62734597, Fax: +86-10-62734597, E-mail: luohailing2014@163.com

2 College of Animal Science and Veterinary Medicine, Heilongjiang Bayi Agricultural University, Daqing 163319, China.

a These two authors contributed equally to the work.

Submitted Dec. 11, 2014; Revised Feb. 5, 2015; Accepted Feb. 13, 2015
}

ventricular arrhythmia and inflammatory or autoimmune diseases (Nuernberg et al., 2005a; Balk et al., 2006), and CLAs have been reported to be beneficial to human health because of their health-promoting properties such as the inhibition of carcinogenesis, a reduced rate of fat deposition, stimulation of the immune system, and reduced serum lipids in animal models (Banni et al., 2002; Wu, 2004). However, an excessive consumption of SFAs such as C12:0, C14:0 and C16:0 may cause an atherogenic potential in humans (Vorster et al., 1997) and may contribute to high coronary heart disease (CHD) mortality rates (Williams, 2000; Rioux and Legrand, 2007). Additionally, a high proportion of $n-6$ PUFA can be deleterious for human health (de Deckere et al., 1998).

It has been confirmed that grazing pastures can produce healthier lamb meat with higher accumulations of CLAs and $n-3$ PUFAs and lower levels SFAs and $n-6 / n-3$ compared to meat from lambs that were fed concentrate (Nuernberg et al., 2005a; Scerra et al., 2007; Nuernberg et 
al., 2008). Grazing is the easiest and most practical method of achieving healthy lamb meat. However, lambs under pure grazing management have poor production performances compared to those that are fed concentrate (Chaturvedi et al., 2003; Demirel et al., 2006) because of the relatively low nutrient values in pastures. Additionally, supplemental feeding can improve the rate of live weight gain and can produce heavier carcasses from grazing livestock (del Campo et al., 2008; Carrasco et al., 2009). And overgrazing results in a decrease of grassland productivity and damages the ecological balance (Zhang et al., 2014); moreover, grassland protection has become a national strategy of sustainable development in China. Therefore, moderate management actions such as adjusting grazing time to obtain preferable performances of high quality lamb meat in an environmentally friendly manner is an important goal.

Restricted grazing time systems can guarantee lambs both access to pastures and abundant energy requirements. The effects of restricted grazing time systems on the pasture intake, milk production and grazing behavior of dairy cows (Kristensen et al., 2007; Perez-Ramirez et al., 2008) and sheep (de Renobales et al., 2012) have previously been studied. In our previous research, we examined restricted grazing time systems on the ingestive behavior, dry matter intake, weight gain and other performances of growing lambs (Xu et al., 2011; Chen et al., 2013; Zhang et al., 2014) and on the grassland (unpublished data); these data showed that moderate grazing time with the proper concentrate is a better way to produce lamb meat when considering animal performance. Additionally, a very long lamb grazing time $(12 \mathrm{~h} / \mathrm{d})$ significantly reduced the quality and productivity of the grassland compared to an area experiencing less grazing hours $(<8 \mathrm{~h} / \mathrm{d})$, but there were no significant differences in the productivity of the grasslands in which lambs grazed for $2 \mathrm{~h} / \mathrm{d}, 4 \mathrm{~h} / \mathrm{d}$, and even $8 \mathrm{~h} / \mathrm{d}$. However, few reports have evaluated the influence of the systems on lambs synthetically, particularly the effects of these systems on the fatty acid composition of the lambs, which is important for meat quality. The present study was conducted to study the effects of different restricted grazing time systems on the production performances and composition of fatty acids in the intramuscular fat (IMF) of growing lambs and to recommend the proper system according to different contexts.

\section{MATERIALS AND METHODS}

\section{Study site and swards}

The present study was conducted in Yanchi County, Ningxia Hui Autonomous Region, China (37\%44 N, $107^{\circ} 19$ $\mathrm{E} ; 1,400 \mathrm{~m}$ above sea level). The site was located in the southwest corner of the Maowusu desert, which belongs to the interim zone of the loess plateau and ordos platform and has a typical temperate continental monsoon climate; the steppe type is classified as arid sandy grassland. The Tan sheep, which is a local breed, is famous for its high-quality meat and skin with long curled wool; these sheep are traditionally raised in the desert and semi-desert areas of the Ningxia Hui Autonomous Region in northwest China.

\section{Animals and experimental design}

In this study, fifty 3-month-old male Tan lambs (with similar body weights) were randomly selected from a local farm (with more than 1,000 lambs) and divided into 5 groups (A, B, C, D, and E) according to different allowances of grazing time. The lambs underwent different feeding strategies for 120 days prior to slaughter. A total of 52-hectares of grassland were fenced off into 4 equal plots, and the lambs in each group (Groups A, B, C, and D) were pastured on their own settled 13-hectare natural grassland plots for $12 \mathrm{~h}, 8 \mathrm{~h}, 4 \mathrm{~h}$, and $2 \mathrm{~h}$ per day, respectively, whereas the lambs in Group E remained indoors. Different gradient commercial supplementary concentrates and hay were supplied to their diet. The detailed information of the feeding strategies is presented in Table 1. Two-week preexperiment was conducted before the normal experiment to determine the quantity of concentrate supplemented making sure lambs could eat up all the concentrate and to let lambs be used to the feeds. And before changing the quantity of concentrate, another two-week transitional period was needed to confirm the quantity of concentrate. The lambs were fed twice per day at 6:00 before grazing and 19:00 after grazing in individual pens. Make sure that the lambs had enough time to take all the concentrate each time. The animals were penned individually except during grazing

Table 1. Different feeding strategies for experimental groups

\begin{tabular}{lcccc}
\hline \multirow{2}{*}{ Group } & \multirow{2}{*}{ Duration of grazing (h/d) } & \multicolumn{3}{c}{ Supplementary concentrate levels } \\
\cline { 3 - 5 } & 12 & First two months (g/d) & Last two months (g/d) & Total (kg) \\
\hline A & 8 & 150 & Non-supplemented & 0 \\
B & 4 & 150 & 300 & 27 \\
C & 2 & 300 & 300 & 27 \\
D & 0 (feedlot) & And hay (full dose) & 500 & 48 \\
E & & And hay (full dose) & 48 \\
& & Angemented & \\
\hline
\end{tabular}


time and had free access to water. All the procedures were conducted following the guidelines of the China Agricultural University Animal Care and Use Committee on animal ethics.

\section{Measurement, sampling and slaughtering procedures}

During the 4-month experimental period, the weight of each lamb was recorded every week, and the average daily gain (ADG) was calculated as the difference between the initial and final body weights. The commercial concentrate, hay and the three main herbages (thyme, licorice, and Caragana) covering more than $80 \%$ (thyme, about 30\%; licorice, about 10\%; Caragana, about $40 \%$ ) of the land were sampled to analyze their chemical compositions. Samples of each type of herbages were cut and collected manually at a height of 1 to $4 \mathrm{~cm}$ from 16 places in every plot at the beginning, middle and end of the experimental period, respectively.

$\mathrm{N}$-alkanes were used to estimate pasture dry matter intake (PDMI) in the middle of July, August, and September. The fecal samples for the dry matter intake (DMI) evaluation were collected from six lambs in each treatment for a 12-day period during each month. Special cloth bags were fastened to the lambs to collect the feces. All the lambs were dosed twice daily at 5:30 before grazing and 19:00 after grazing with a pellet that contained $60 \mathrm{mg}$ of C32-alkane. Fecal samples were collected from each lamb twice daily at the time the lambs were dosed after the 7 th day of dosing. During the periods of fecal sample collection, herbage samples were obtained for chemical analysis.

After 120 days, all the lambs were slaughtered at a local commercial abattoir. Before being slaughtered, the lambs were prevented from consuming food for $24 \mathrm{~h}$ and from drinking for $8 \mathrm{~h}$. After slaughter, the carcasses were weighed, and enough muscle samples (about $250 \mathrm{~g}$ ) were collected randomly from the whole chopped longissimus dorsi muscle for fatty acid and IMF measurement. All the samples were stored at $-80^{\circ} \mathrm{C}$ until analysis.

\section{Chemical analyses}

The dry matter (DM) of the concentrate, pastures, hay and fecal samples were analyzed according to the Association of Official Analytical Chemists (AOAC, 1995, method no. 950.46). The crude protein (CP) (method no. 984.13) and ash (method no. 920.153) levels of the feeds were also measured according to the AOAC (1995) procedures. Neutral detergent fiber (NDF) and acid detergent fiber values were determined using the filter bag technique (ANKOM 2000, Fairport, NY, USA) and the reagents described by Vansoest et al. (1991). The $n$-alkane contents of the concentrate, hay, pastures and feces were measured using the method of Lin et al. (2006). PDMI was estimated using the $n$-alkane method (Mayes and Dove, 2000) and was calculated with the equation described by Kennedy et al. (2011). The formula used is shown below:

\section{Calculated $\mathrm{Fi}=$ pasture $\mathrm{DMI} \times \mathrm{Pi}$ +hay $\mathrm{DMI} \times \mathrm{Hi}+$ concentrate $\mathrm{DMI} \times \mathrm{Ci}$ + Dosei/fecal DM output}

in which $\mathrm{Fi}, \mathrm{Pi}, \mathrm{Hi}$, and $\mathrm{Ci}$ were the concentrations $(\mathrm{mg} / \mathrm{kg}$ $\mathrm{DM})$ of $n$-alkane $\mathrm{i}$ in the feces, pasture, hay and concentrate, respectively. Dosei was the amount of $n$-alkane in the daily dose. Thus, the average total dry matter intake (TDMI) could be determined using the sums of the PDMI and the concentrate dry matter intake.

Intramuscular fat was measured by the Soxhlet extraction 920.39 method according to the AOAC (1995). To determine the fatty acid composition, $0.30 \mathrm{~g}$ of feed samples and $0.15 \mathrm{~g}$ of vacuum dried meat samples were first solubilized into the mobile phase (a $4 \mathrm{~mL}$ solution consisting of ethanol chloride and methanol [1/10, v/v], 1 $\mathrm{mL}$ of hexane, and $1 \mathrm{~mL}$ of C11:0 [1 mg/mL]). All the samples were then incubated in an $80^{\circ} \mathrm{C}$ water bath for $2 \mathrm{~h}$. Subsequently, a $7 \%$ potassium carbonate solution $(5 \mathrm{~mL})$ was added, and the mixture was centrifuged at 1,200 rpm for $5 \mathrm{~min}$. The organic phase was separated and filtered through a filter membrane with a pore size of $0.5 \mu \mathrm{m}$.

The fatty acids were quantified using gas chromatography (Agilent, 6890; Agilent Technologies, Santa Clara, CA, USA) equipped with a DB-23 capillary column $(60.0 \mathrm{~m} \times 250 \mu \mathrm{m} \times 0.25 \mu \mathrm{m})$ and a flame ionization detector. One microliter of each sample was used to detect the fatty acid composition; the temperatures of the injector and detectors were $260^{\circ} \mathrm{C}$ and $270^{\circ} \mathrm{C}$, respectively. Nitrogen (2.0 $\mathrm{mL} / \mathrm{min}$ ) was used as the gas vector, and the identification of the fatty acids was performed using the standard samples mixture. The quantities of the fatty acids were calculated using chromatogram peak areas and expressed as g/100 $\mathrm{g}$ of total fatty acid (meat samples) and $\mathrm{mg} / \mathrm{g}$ of DM (feed samples).

In all the feed chemical analyses, three repetitions of each sample were measured, and the results are reported by their means in Table 2.

\section{Statistical analysis}

Data of animal productive performances and fatty acid compositions of longissimus dorsi were analyzed using the general linear model procedure (SAS 8.2, Institute Inc., Cary, NC, USA). The means were compared using a oneway analysis of variance to determine the levels of statistical significance. Differences were considered to be significant at $\mathrm{p}<0.05$. 
Table 2. Ingredients, chemical composition, and fatty acid profile of concentrate, herbages and hay

\begin{tabular}{|c|c|c|c|c|c|}
\hline \multirow{2}{*}{ Items } & \multirow{2}{*}{ Concentrate } & \multicolumn{3}{|c|}{ Herbages $^{1}$} & \multirow{2}{*}{ Hay } \\
\hline & & Thyme & Licorice & Caragana & \\
\hline \multicolumn{6}{|l|}{ 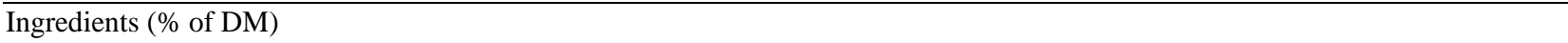 } \\
\hline Corn & 59.5 & & & & \\
\hline Wheat bran & 10.0 & & & & \\
\hline Soybean meal & 25.5 & & & & \\
\hline Premix $^{2}$ & 5.0 & & & & \\
\hline \multicolumn{6}{|l|}{ Chemical composition (\% of DM) } \\
\hline $\mathrm{DM}$ & 87.5 & 40.89 & 33.88 & 30.79 & 85.99 \\
\hline $\mathrm{CP}$ & 19.10 & 9.00 & 18.81 & 21.93 & 10.33 \\
\hline Ash & 3.20 & 12.10 & 23.40 & 6.92 & 8.75 \\
\hline $\mathrm{NDF}$ & 13.50 & 43.83 & 34.10 & 32.94 & 50.70 \\
\hline $\mathrm{ADF}$ & 6.00 & 39.10 & 31.71 & 32.03 & 37.42 \\
\hline Digestible energy $^{3}(\mathrm{MJ} / \mathrm{kg} \mathrm{DM})$ & 15.0 & & & & \\
\hline \multicolumn{6}{|l|}{ Fatty acid profile (mg/g of DM) } \\
\hline $\mathrm{C} 14: 0$ & 2.87 & 0.14 & 0.70 & 0.22 & 0.23 \\
\hline $\mathrm{C} 16: 0$ & 16.60 & 3.32 & 5.08 & 5.20 & 4.85 \\
\hline C18:0 & 14.85 & 0.55 & 1.11 & 1.03 & 0.97 \\
\hline $\mathrm{C} 18: 1 n 9$ & 31.20 & 2.07 & 0.83 & 0.76 & 0.73 \\
\hline $\mathrm{C} 18: 2 n 6$ & 2.10 & 3.02 & 2.80 & 3.37 & 3.01 \\
\hline $\mathrm{C} 18: 3 n 3$ & 0.71 & 6.21 & 7.02 & 6.09 & 6.17 \\
\hline$\Sigma \mathrm{TFA}$ & 74.16 & 16.48 & 23.62 & 19.36 & 15.98 \\
\hline$\Sigma \mathrm{SFA}$ & 37.15 & 5.31 & 12.90 & 9.36 & 7.09 \\
\hline$\Sigma$ UFA & 37.00 & 11.10 & 10.47 & 9.98 & 8.91 \\
\hline
\end{tabular}

DM, dry matter; CP, crude protein; NDF, neutral detergent fiber; ADF, acid detergent fiber; TFA, total fatty acids; SFA, saturated fatty acids; UFA, unsaturated fatty acids.

${ }^{1}$ Results are the average of the analyses of the herbage collected at the beginning, in the middle and at the end of the experimental period. The estimated chemical compositions of total herbages (\% of DM): DM, 34.96; CP, 16.69; Ash, 10.92; NDF, 40.17; ADF, 34.64.

${ }^{2}$ Basal ingredients of the premix: bentonite, salt, sodium bicarbonate, limestone, calcium hydrogen phosphate, antioxidant, magnesium oxide, flavor agents, enzyme preparation, probiotics, trace elements, vitamins. The premix per kilogram contains the following material: vitamin A (retinyl acetate), $120,000 \mathrm{IU}$; vitamin $\mathrm{D}_{3}$, 18,000 IU; vitamin E (DL- $\alpha$-tocopheryl acetate), $500 \mathrm{IU}$; iron, $900 \mathrm{mg}$; copper, $150 \mathrm{mg}$; manganese, 1,160 mg; zinc, 1,900 mg; iodine, 11,000 mg; and selenium, $6 \mathrm{mg}$; cobalt, $6 \mathrm{mg}$; Ca $100 \mathrm{~g}$; P $30 \mathrm{~g}$; salt, $150 \mathrm{~g}$.

${ }^{3}$ Calculated values. Digestible energy of concentrate $=16.90(\mathrm{MJ} / \mathrm{kg}$ DM of corn $) \times 0.595+13.24(\mathrm{MJ} / \mathrm{kg} \mathrm{DM}$ of Wheat bran $) \times 0.10+14.20(\mathrm{MJ} / \mathrm{kg} \mathrm{DM}$ of Soybean meal) $\times 0.255$.

\section{RESULTS}

\section{Chemical composition of diets and feed fatty acids}

The chemical compositions and fatty acid compositions of the feeds are presented in Table 2. All three types of herbages and hay contained much higher NDF levels than the concentrate feed, and there were higher $\mathrm{CP}$ values in the Caragana; but lower $\mathrm{CP}$ values in thyme, licorice and hay than the concentrate. With respect to fatty acid composition, the concentrate, which had much lower levels of C18:3n3, had higher levels of C16:0, C18:0, and C18:1n9 than the pasture feeds. Additionally, the C18:2n6 level measured in the concentrate was lower than that of the pastures. The herbages displayed little differences in their fatty acid compositions, and the composition of fatty acids in the hay was similar to the three types of herbages. In total, the concentrate feed contained a much greater content of total unsaturated fatty acids (UFAs) and total SFAs because of its higher total fatty acid content than the herbages.

\section{Feed intake and lamb performances}

The PDMI and TDMI of the lambs in the five treatments in July, August, and September are reported in Table 3. It is clear that PDMI increased with an increase in grazing time. Additionally, the indoor-fed lambs (Group E) had higher PDMI values than Group D but lower PDMI values than Group C; however, the differences were not significant between the three groups. The relative relationships between the PDMI of the treatments were similar during the three months whereas the individual values increased each month. By contrast, the TDMI of the lambs from the five groups showed no significant differences but increased with time.

The body weights, ADG, carcass weights and IMF contents are shown in Table 4. Lambs from the five treatments had different final values before slaughter although they had the same initial body weights. The lambs in Group D had the largest final body weights whereas the lambs in Groups A and E had the smallest final body 
Table 3. Pasture, concentrate and total dry matter intake (g/d) in July, August, and September ${ }^{1}$

\begin{tabular}{|c|c|c|c|c|c|}
\hline \multirow{2}{*}{ Items } & \multicolumn{5}{|c|}{ Treatments } \\
\hline & A & $\mathrm{B}$ & $\mathrm{C}$ & $\mathrm{D}$ & E \\
\hline \multicolumn{6}{|c|}{ Pasture dry matter intake (g/d) } \\
\hline July & $953.86 \pm 90.8^{\mathrm{c}}$ & $861.95 \pm 93.1^{\mathrm{bc}}$ & $685.42 \pm 61.6^{\mathrm{ab}}$ & $487.75 \pm 48.9^{\mathrm{a}}$ & $556.26 \pm 47.2^{\mathrm{ab}}$ \\
\hline August & $1,145.30 \pm 181.6^{\mathrm{c}}$ & $992.97 \pm 220.6^{b c}$ & $732.35 \pm 28.7^{\mathrm{abc}}$ & $491.21 \pm 66.8^{\mathrm{a}}$ & $667.55 \pm 62.5^{\mathrm{ab}}$ \\
\hline September & $1,206.23 \pm 168.4^{\mathrm{c}}$ & $1,096.39 \pm 128.5^{\mathrm{bc}}$ & $878.05 \pm 57.0^{\mathrm{ab}}$ & $570.37 \pm 19.9^{\mathrm{a}}$ & $780.46 \pm 44.6^{\mathrm{a}}$ \\
\hline \multicolumn{6}{|c|}{ Concentrate dry matter intake $(\mathrm{g} / \mathrm{d})$} \\
\hline July & - & 131.25 & 131.25 & 262.5 & 262.5 \\
\hline August & - & 262.5 & 262.5 & 437.5 & 437.5 \\
\hline September & - & 262.5 & 262.5 & 437.5 & 437.5 \\
\hline \multicolumn{6}{|c|}{ Total dry matter intake $(\mathrm{g} / \mathrm{d})$} \\
\hline July & $953.86 \pm 90.8$ & $998.44 \pm 93.1$ & $821.91 \pm 61.6$ & $760.72 \pm 48.9$ & $829.23 \pm 47.2$ \\
\hline August & $1,145.30 \pm 181.6$ & $1,265.94 \pm 220.6$ & $1,005.32 \pm 28.7$ & $946.16 \pm 66.8$ & $1,122.50 \pm 62.5$ \\
\hline September & $1,206.23 \pm 168.4$ & $1,369.36 \pm 128.5$ & $1,151.02 \pm 57.0$ & $1,025.32 \pm 19.9$ & $1,235.41 \pm 44.6$ \\
\hline
\end{tabular}

${ }^{1}$ See Table 1 for administration of each group (A-E).

The values are the means \pm standard error. Means without a common letter differ significantly $(\mathrm{p}<0.05)$.

weights. Therefore, the lambs in Group D had the highest ADG, the lambs in Groups B, and $\mathrm{C}$ had medium ADG values, and the lambs in Group A had the smallest ADG. In total, the carcass weights of the lambs of all groups followed the same principles, with the largest carcass weights in Group D, moderate weights in Groups B and C, and the smallest weights in Groups A and E. However, a different principle was found regarding the fat content of the longissimus dorsi muscle. Relatively higher IMF contents were detected in the muscles of Groups B, C, D, and $\mathrm{E}$, between which there were no obvious differences existing, and lower values were only found in Group A.

\section{Fatty acid composition of intramuscular fat}

The composition of fatty acids in the longissimus dorsi muscle is reported in Table 5. The different restricted grazing time systems had no significant effects on the levels of C18:0, which is the most SFA in IMF ( $>>0.05)$. However, higher levels of concentrate in the diets increased the proportion of C16:0, which is another highly SFA. The C16:0 levels of the lambs fed with higher amounts of concentrate in Groups D and $\mathrm{E}$ were relatively higher than in the lambs in Groups A and B $(\mathrm{p}<0.05)$, which consumed less or no concentrate in their diets. Regarding the other individual SFAs, the lambs with increased durations of grazing and reduced or no supplementary feeding (Groups $\mathrm{A}$ and $\mathrm{B}$ ) resulted in lower levels of C12:0 and C14:0 in the IMF than the lambs (Groups D and E) that had received relatively higher amounts of concentrate with shorter or no grazing time $(\mathrm{p}<0.05)$. Meanwhile, differences in monounsaturated fatty acids (MUFAs) were also observed among the five treatments in IMF. The proportions of C18:1n9, which is the most common MUFA, in Groups C, $\mathrm{D}$ and $\mathrm{E}$ were significantly higher than the proportions in Group A in the muscle fat $(\mathrm{p}<0.05)$. Additionally, a longer grazing time and less or no concentrate (Group A and B) resulted in less $\mathrm{C} 14: 1$ and $\mathrm{C} 16: 1$ fatty acids in the muscle fat $(p<0.05)$. Notably, different treatments had no significant differences regarding the values of C18:1trans because of their large standard errors. C18:2n6c and C20:4n6 were the most abundant PUFAs in the longissimus dorsi muscle. Additionally, a longer grazing time with less supplementary feeding resulted in more $\mathrm{C} 18: 2 n 6 c$ in the lamb meat $(\mathrm{p}<0.05)$, which can be observed by comparing the values of each group. However, the results showed that the different grazing systems in the experiment had no

Table 4. Body weights, average daily gains, carcass weights and IMF contents of Tan lambs under different restricted grazing time systems $^{1}$

\begin{tabular}{lccccc}
\hline \multirow{2}{*}{ Items } & \multicolumn{5}{c}{ Treatments } \\
\cline { 2 - 6 } & \multicolumn{1}{c}{$\mathrm{A}$} & $\mathrm{B}$ & $\mathrm{C}$ & $\mathrm{D}$ & $\mathrm{E}$ \\
\hline Initial body weight $(\mathrm{kg})$ & $16.29 \pm 0.60$ & $15.05 \pm 0.67$ & $15.28 \pm 0.86$ & $15.67 \pm 0.81$ & $15.79 \pm 0.83$ \\
Final body weight $(\mathrm{kg})$ & $26.22 \pm 0.81^{\mathrm{a}}$ & $30.45 \pm 0.94^{\mathrm{bc}}$ & $27.80 \pm 1.17^{\mathrm{ab}}$ & $31.06 \pm 0.96^{\mathrm{c}}$ & $27.42 \pm 0.85^{\mathrm{a}}$ \\
Average daily gain $(\mathrm{g})$ & $101.35 \pm 5.61^{\mathrm{a}}$ & $157.16 \pm 7.88^{\mathrm{c}}$ & $127.76 \pm 7.40^{\mathrm{b}}$ & $157.02 \pm 4.78^{\mathrm{c}}$ & $118.65 \pm 6.05^{\mathrm{ab}}$ \\
Carcass weight $(\mathrm{kg})$ & $10.21 \pm 0.35^{\mathrm{a}}$ & $12.55 \pm 0.58^{\mathrm{b}}$ & $11.93 \pm 0.55^{\mathrm{b}}$ & $14.11 \pm 0.60^{\mathrm{c}}$ & $9.96 \pm 0.47^{\mathrm{a}}$ \\
IMF content $(\%)$ & $2.00 \pm 0.18^{\mathrm{a}}$ & $3.93 \pm 0.63^{\mathrm{b}}$ & $2.97 \pm 0.43^{\mathrm{ab}}$ & $3.81 \pm 0.33^{\mathrm{b}}$ & $3.62 \pm 0.52^{\mathrm{b}}$ \\
\hline
\end{tabular}

IMF, intramuscular fat.

${ }^{1}$ See Table 1 for administration of each group (A-E).

The values are the means \pm standard error $(n=10$ per group). Different superscripts mean significant differences $(\mathrm{p}<0.05)$. 
Table 5. Fatty acid profile (g/100 g of total fatty acid) of longissimus dorsi in Tan lambs ${ }^{1}$

\begin{tabular}{|c|c|c|c|c|c|}
\hline \multirow{2}{*}{ Items } & \multicolumn{5}{|c|}{ Treatments } \\
\hline & $\mathrm{A}$ & $\mathrm{B}$ & $\mathrm{C}$ & $\mathrm{D}$ & $\mathrm{E}$ \\
\hline \multicolumn{6}{|c|}{ Saturated fatty acids } \\
\hline C6:0 & $0.01 \pm 0.01$ & $0.02 \pm 0.01$ & $0.02 \pm 0.00$ & $0.01 \pm 0.00$ & $0.01 \pm 0.00$ \\
\hline C8:0 & $0.00 \pm 0.00^{\mathrm{c}}$ & $0.01 \pm 0.00^{\mathrm{bc}}$ & $0.02 \pm 0.00^{\mathrm{abc}}$ & $0.02 \pm 0.00^{\mathrm{ab}}$ & $0.02 \pm 0.01^{\mathrm{a}}$ \\
\hline C10:0 & $0.11 \pm 0.01^{\mathrm{c}}$ & $0.11 \pm 0.00^{\mathrm{bc}}$ & $0.12 \pm 0.01^{\mathrm{bc}}$ & $0.14 \pm 0.01^{\mathrm{ab}}$ & $0.17 \pm 0.01^{\mathrm{a}}$ \\
\hline $\mathrm{C} 12: 0$ & $0.10 \pm 0.01^{\mathrm{bc}}$ & $0.09 \pm 0.01^{\mathrm{b}}$ & $0.15 \pm 0.01^{\mathrm{a}}$ & $0.15 \pm 0.03^{\mathrm{a}}$ & $0.15 \pm 0.02^{\mathrm{a}}$ \\
\hline $\mathrm{C} 14: 0$ & $1.47 \pm 0.09^{\mathrm{b}}$ & $1.62 \pm 0.14^{\mathrm{b}}$ & $2.24 \pm 0.11^{\mathrm{a}}$ & $2.10 \pm 0.22^{\mathrm{a}}$ & $2.44 \pm 0.17^{\mathrm{a}}$ \\
\hline $\mathrm{C} 15: 0$ & $0.50 \pm 0.05$ & $0.45 \pm 0.05$ & $0.49 \pm 0.05$ & $0.48 \pm 0.02$ & $0.45 \pm 0.04$ \\
\hline $\mathrm{C} 16: 0$ & $18.01 \pm 0.60^{\mathrm{c}}$ & $19.86 \pm 0.75^{\mathrm{b}}$ & $20.57 \pm 0.26^{\mathrm{ab}}$ & $21.51 \pm 0.41^{\mathrm{ab}}$ & $22.22 \pm 0.82^{\mathrm{a}}$ \\
\hline $\mathrm{C} 17: 0$ & $1.48 \pm 0.07$ & $1.37 \pm 0.07$ & $1.39 \pm 0.06$ & $1.26 \pm 0.05$ & $1.37 \pm 0.08$ \\
\hline $\mathrm{C} 18: 0$ & $24.10 \pm 1.16$ & $24.86 \pm 1.02$ & $23.80 \pm 1.04$ & $22.06 \pm 1.24$ & $24.71 \pm 1.41$ \\
\hline \multicolumn{6}{|c|}{ Monounsaturated fatty acids } \\
\hline $\mathrm{C} 14: 1$ & $0.02 \pm 0.01^{\mathrm{b}}$ & $0.03 \pm 0.01^{\mathrm{b}}$ & $0.06 \pm 0.01^{\mathrm{a}}$ & $0.09 \pm 0.01^{\mathrm{a}}$ & $0.08 \pm 0.01^{\mathrm{a}}$ \\
\hline C16:1 & $1.02 \pm 0.04^{\mathrm{ab}}$ & $1.18 \pm 0.05^{\mathrm{ab}}$ & $1.20 \pm 0.06^{\mathrm{ab}}$ & $1.47 \pm 0.09^{\mathrm{c}}$ & $1.30 \pm 0.13^{\mathrm{bc}}$ \\
\hline C18:1trans & $0.56 \pm 0.06$ & $1.03 \pm 0.35$ & $0.56 \pm 0.03$ & $0.49 \pm 0.10$ & $0.33 \pm 0.11$ \\
\hline $\mathrm{C} 18: 1 n-9$ & $31.31 \pm 1.29^{\mathrm{a}}$ & $34.09 \pm 1.38^{\mathrm{ab}}$ & $36.33 \pm 0.78^{b}$ & $37.18 \pm 0.77^{\mathrm{b}}$ & $36.28 \pm 1.23^{\mathrm{b}}$ \\
\hline C20:1 & $0.14 \pm 0.02$ & $0.14 \pm 0.02$ & $0.17 \pm 0.03$ & $0.12 \pm 0.01$ & $0.11 \pm 0.01$ \\
\hline $\mathrm{C} 24: 1$ & $0.15 \pm 0.04$ & $0.10 \pm 0.02$ & $0.10 \pm 0.01$ & $0.12 \pm 0.01$ & $0.13 \pm 0.02$ \\
\hline \multicolumn{6}{|c|}{ Polyunsaturated fatty acids } \\
\hline $\mathrm{C} 18: 2 n 6 t$ & $0.79 \pm 0.22$ & $0.56 \pm 0.20$ & $0.60 \pm 0.17$ & $0.62 \pm 0.12$ & $0.48 \pm 0.02$ \\
\hline $\mathrm{C} 18: 2 n 6 c$ & $9.03 \pm 0.86^{\mathrm{a}}$ & $8.64 \pm 0.92^{\mathrm{a}}$ & $6.34 \pm 0.60^{\mathrm{b}}$ & $6.97 \pm 0.45^{\mathrm{ab}}$ & $5.50 \pm 0.54^{\mathrm{b}}$ \\
\hline $\mathrm{C} 18: 3 n 6$ & $0.35 \pm 0.02^{\mathrm{c}}$ & $0.30 \pm 0.01^{\mathrm{b}}$ & $0.25 \pm 0.01^{\mathrm{a}}$ & $0.23 \pm 0.01^{\mathrm{a}}$ & $0.23 \pm 0.02^{\mathrm{a}}$ \\
\hline $\mathrm{C} 18: 3 n 3$ & $2.17 \pm 0.22^{\mathrm{d}}$ & $1.60 \pm 0.15^{\mathrm{c}}$ & $1.11 \pm 0.13^{\mathrm{b}}$ & $0.77 \pm 0.04^{\mathrm{b}}$ & $0.31 \pm 0.02^{\mathrm{a}}$ \\
\hline $\mathrm{C} 20: 4 n 6$ & $4.16 \pm 0.67$ & $3.29 \pm 0.65$ & $2.70 \pm 0.35$ & $2.80 \pm 0.36$ & $2.12 \pm 0.33$ \\
\hline $\mathrm{C} 20: 5 n 3$ & $0.98 \pm 0.13^{\mathrm{d}}$ & $0.68 \pm 0.13^{\mathrm{c}}$ & $0.45 \pm 0.08^{\mathrm{bc}}$ & $0.33 \pm 0.04^{\mathrm{ab}}$ & $0.10 \pm 0.02^{\mathrm{a}}$ \\
\hline CLA- $c 9 t 11$ & $0.27 \pm 0.02$ & $0.23 \pm 0.06$ & $0.31 \pm 0.06$ & $0.22 \pm 0.06$ & $0.18 \pm 0.03$ \\
\hline CLA- $t 10 c 12$ & $0.08 \pm 0.03$ & $0.10 \pm 0.02$ & $0.12 \pm 0.01$ & $0.10 \pm 0.00$ & $0.07 \pm 0.01$ \\
\hline \multicolumn{6}{|l|}{ Sums and ratios } \\
\hline$\Sigma$ SFA & $48.00 \pm 1.06$ & $49.10 \pm 1.74$ & $49.39 \pm 1.13$ & $48.22 \pm 1.24$ & $52.10 \pm 1.51$ \\
\hline$\Sigma$ MUFA & $33.52 \pm 1.20^{\mathrm{a}}$ & $36.58 \pm 1.19^{\mathrm{ab}}$ & $38.46 \pm 0.79^{\mathrm{b}}$ & $39.50 \pm 0.82^{\mathrm{b}}$ & $38.67 \pm 1.27^{\mathrm{b}}$ \\
\hline$\Sigma$ PUFA & $16.30 \pm 1.90^{\mathrm{a}}$ & $14.78 \pm 1.90^{\mathrm{ab}}$ & $11.04 \pm 1.20^{\mathrm{bc}}$ & $11.51 \pm 0.96^{\mathrm{bc}}$ & $8.91 \pm 0.91^{\mathrm{c}}$ \\
\hline$\Sigma n-3 \mathrm{FA}$ & $3.35 \pm 0.44^{\mathrm{d}}$ & $2.28 \pm 0.28^{c}$ & $1.60 \pm 0.23^{\mathrm{bc}}$ & $1.10 \pm 0.08^{\mathrm{ab}}$ & $0.42 \pm 0.03^{\mathrm{a}}$ \\
\hline$\Sigma n-6 \mathrm{FA}$ & $14.34 \pm 1.65^{\mathrm{a}}$ & $13.28 \pm 1.74^{\mathrm{ab}}$ & $9.89 \pm 1,04^{\mathrm{bc}}$ & $10.71 \pm 0.88^{\mathrm{bc}}$ & $8.50 \pm 0.89^{c}$ \\
\hline$\Sigma n-3 / \Sigma n-6$ & $0.23 \pm 0.01^{\mathrm{a}}$ & $0.18 \pm 0.01^{\mathrm{b}}$ & $0.16 \pm 0.01^{\mathrm{c}}$ & $0.10 \pm 0.00^{\mathrm{d}}$ & $0.05 \pm 0.00^{\mathrm{e}}$ \\
\hline
\end{tabular}

CLA, conjugated linoleic acids; SFA, saturated fatty acids; MUFA, monounsaturated fatty acids; PUFA, polyunsaturated fatty acids; FA, fatty acids.

${ }^{1}$ See Table 1 for administration of each group (A-E).

The values are the means \pm standard error $(\mathrm{n}=10$ per group). Different superscripts mean significant differences $(\mathrm{p}<0.05)$.

effects on C20:4n6 in the IMF. Regarding C18:3n3, more accumulations occurred in the meat of lambs that had more allowance to pasture but received less concentrate $(p<0.05)$. Regarding the other individual fatty acids, a similar rule as that of $\mathrm{C} 18: 3 n 3$ was detected in $\mathrm{C} 18: 2 n 6 c, \mathrm{C} 18: 3 n 6$, and $\mathrm{C} 20: 5 n 3$ in the longissimus dorsi muscle: as the amount of time spent grazing decreased and the amount of concentrate consumed increased (Group A to E), the levels of these fatty acids gradually decreased although the situations of significance varied among the fatty acids and groups. Additionally, the treatments did not result in obviously different values of $\mathrm{C} 18: 2 n 6 t$.

In the IMF, the proportion of total SFAs was the greatest out of the three types of fatty acids (SFA, MUFA, and PUFA), and the smallest proportion was of PUFA. Different restricted grazing strategies had no obvious significant effects on the total SFA proportions in IMF ( $p>0.05$ ), but they significantly affected the total MUFA and total PUFA proportions. The lambs in Groups C, D, and E had significantly higher proportions of total MUFA in the longissimus dorsi muscle than Group A $(\mathrm{p}<0.05)$. The proportion of total PUFAs in Group A was significantly higher than that of Groups C, D, and E $(\mathrm{p}<0.05)$ in the muscle fat, and the proportions decreased by group as the pasture allowance shortened and the amount of concentrate consumed increased. The proportions of total $n$-3 PUFAs and $n-6$ PUFAs of the lamb meat in the five groups followed the same principle in that the values gradually decreased with the reduction of grazing and the increase of concentrate consumed. Meanwhile, the restricted grazing 
systems had a remarkable effect on the ratio of $n-3 / n-6$ in the IMF with the highest levels appearing in Group A $(\mathrm{p}<0.05)$ and lower values present in Groups B, C, D, and E (obviously different from one another). The proportion of CLAs (CLA- $c 9 t 11$, and CLA- $t 10 c 12$ ) was also examined, but no significant differences were detected in the muscle fat among the treatments $(\mathrm{p}>0.05)$.

\section{DISCUSSION}

\section{Feed intake and lamb performance}

The animal response to a diet depends on the type, amount and time of feeding. Dairy cows can modify their intake rates in response to a constraint of access to pastures to maintain their intake and nutrient supply (Perez-Ramirez et al., 2008). In previous studies, we detected that lambs under shorter grazing time systems always had higher pasture intake rates and higher intake time percentages during grazing (Chen et al., 2013; Zhang et al., 2014). Lambs must improve their efficiency of grazing activities to consume more fresh pasture in a limited time. However, lambs with longer grazing time allowances consumed more pasture per day because of the reduced concentrate in their daily diets (Zhang et al., 2014). The results of the present study corresponded to previous studies. The lambs in Groups A, B, and C, which had relatively longer grazing times and received less concentrate, had higher PDMI values than the lambs in Group D, which grazed only $2 \mathrm{~h}$ but were fed abundant amounts of concentrate. In Group E, the lambs consumed an identical amount of concentrate as Group D, and they had slightly higher PDMI values than the lambs in Group D because of their free access to hay. In total, both grazing time and supplemental concentrate were factors that determined the PDMI values of the lambs. Therefore, as expected, the TDMI of the lambs in the five treatments had no obvious differences. It was an inevitable and understandable result that both PDMI and TDMI increased with the time because the lambs required more energy and nutrients as they grew.

Concentrates or grains have more energy concentrations than herbage feeds. In general, when pastures and grains or concentrates are offered ad libitum, the ADG is higher in concentrate-fed cattle relative to grass-fed animals (French et al., 2001). Del Campo's research on cattle has confirmed this conclusion (del Campo et al., 2008). Several authors (McClure et al., 1994; Zervas et al., 1999) have reported greater ADG in drylot lambs than in grazing lambs although their lambs were raised on different types of pasture. In our study, we obtained the same conclusion that lambs that consumed concentrate in their diets resulted in greater ADG compared to lambs that purely grazed. In addition, by comparing Groups B and $\mathrm{C}$, we showed that at a similar concentrate intake, more grazing time improved the ADG of lambs although the energy from the pasture was relatively low. The ADG of the lambs in Group D was greater than that in Group E mainly because of the higher quality of fresh herbages than the hay fed indoors (Table 2). Previous studies have shown that lambs fed at higher planes of nutrition have greater growth rates compared to lambs fed at lower planes of nutrition (Lee, 1986). The lambs that received a high percentage of high-class feeds (Groups B and D) had a greater ADG than the lambs that received less because the TDMI of all the lambs did not change significantly. Hence, after the same 120-day period, the lambs in Groups B and D achieved relatively higher final body weights than the animals in the other groups.

Concentrate supplementation affected not only individual performance but also carcass traits of grazing livestock (Atti and Mahouachi, 2009). In the present study, the lambs in Groups B (took more concentrate than Group A, longer grazing time than Group C), D, and E received more concentrate and had relatively higher IMF contents in the longissimus dorsi muscle than those in Groups A and C (Table 4). Aurousseau et al. (2004) and Nuernberg et al. (2005b) observed the same situation in IMF content whereas Velasco et al. (2004) and Carrasco et al. (2009) found that this phenomenon occurs in carcass fat as well. Vermorel (1988) believed that the lower energy supply (poor vegetation and an insufficient amount of added concentrate) and higher energy expenditures as a result of having to walk and thermoregulation were responsible for the situations. Notably, it has been confirmed that the fat in meat contributes to the eating quality of the meat (Webb, 2006). The chemical and physical properties of fat influence the eating and keeping qualities of meat (Kempster et al., 1982). Reducing the fat content in meat may adversely affect eating satisfaction. Therefore, consumers prefer lamb meat containing slightly higher IMF content, although consuming large amounts of fat has been shown to be harmful to humans. There are much lower levels of lipids in lamb meat compared to other meats such as pork, which makes lamb meat healthier (Wood et al., 2008). In addition, the carcass weights of the lambs were similar to the patterns of ADG and body weights in that Group D had the highest value, Groups B and C had moderate values, and the lowest values were present in Groups A and E. This outcome may have also been caused by the variety of energy and nutrition in the lambs' diets from the different treatments.

\section{Muscle fatty acid composition}

In the present study, different restricted grazing time systems significantly influenced the SFA proportions in the muscle fat of Tan lambs. Short-chain fatty acids (with 10 or less carbon atoms) were hardly detected in longissimus dorsi muscles, and German and Dillard (2006) have noted that short-chain fatty acids are directly absorbed into the 
portal vein and metabolized in the liver to obtain metabolic energy instead of being transported by chylomicrons to adipose tissue. Because the SFAs C12:0, C14:0, and C16:0 increase the synthesis of cholesterol and favor the accumulation of low density lipoproteins, they are a major risk factor for cardiovascular diseases in humans (Moloney et al., 2001). Researchers have found that grass intake can significantly decrease the levels of SFA in the muscles of lambs (Bas and Morand-Fehr, 2000; Velasco et al., 2001), but our results did not show significantly differences among the treatments though lambs in Group E got a larger number value of total SFA. The lambs with longer grazing time allowances in Groups A and B accumulated less C12:0, C14, and $\mathrm{C} 16: 0$ than the lambs that were fed concentrate-based diets. Therefore, consumers may prefer lamb meat from animals that consumed more herbages instead of main concentrate. We did not find significant differences of C18:0 proportions which has a neutral effect towards humans (Bonanome and Grundy, 1988) among the treatments, which was consistent with the results of Velasco et al. (2001). Actually, due to the hydrogenation of rumen microbes, the majority of PUFA in pastures are converted into SFA in the rumen, only a small percentage of PUFA escapes (Wood et al., 2008). Therefore, the C18:0 in rumen of pasture-fed lambs (higher PUFA in their feed) may not show decrease than the concentrate-fed lambs at the base of same DMI. That's why higher concentrate contained high level of C18:0 did not result in higher C18:0 in the muscle. In the rumen, $\Delta 9$ desaturase is an important enzyme that has been shown to control the degree of unsaturation. It can convert $\mathrm{C} 16: 0$ and $\mathrm{C} 18: 0$ into $\mathrm{C} 16: 1$ and $\mathrm{C} 18: 1$, respectively. In the present study, more $\mathrm{C} 16: 1$ was present in the lamb muscles of Group D, which consisted of the lambs that received the most abundant amounts of concentrate and only 2 hours of grazing time per day. The $\Delta 9$ desaturase activity was down regulated by PUFAs (Yang et al., 1999; Ntambi and Bene, 2001), which were more common in the rumens of lambs with pasture-based diets. C18:1n9 was the major MUFA in the lamb muscle fat, and the lambs that received more concentrate and had less grazing hours displayed greater proportions of this fatty acid than the lambs under the longer grazing time system; this result was in agreement with the fatty acid proportions of the diets. This finding was consistent with that of Velasco et al. (2004) and was a reasonable result of the down regulated activity of $\Delta 9$ desaturase in grazing lambs. However, some researchers who believed C18:1 $n 9$ originated from biohydrogenation in the rumen regarded this as a response of the dietary forage/feed ratio. A higher proportion of $\mathrm{C} 18: 1 n 9$ in lamb (with a concentrate-based diet) muscle fat was a result of the presence of a greater proportion of available carbohydrates, which reduced the stay of food in the rumen and decreased the biohydrogenation of the polyenoic fatty acids (Petrova et al., 1994).

A significant proportion of muscle fat is phospholipids, which have a high PUFA proportion to perform their function as constituents of cellular membranes (Wood et al., 2008). Pastures, with abundant PUFAs (over $50 \%$ of total fatty acids), are the main sources of PUFAs for ruminants. In ruminants, approximately $10 \%$ of their dietary PUFAs are available for incorporation into tissue lipids in both sheep and cattle (Wood et al., 2008), and others are degraded into monounsaturated and SFAs in the rumen by microbial biohydrogenation. In general, C18:2n-6 is the most abundant PUFA in lamb meat (Diaz et al., 2005). It was reported that lambs fed on concentrate showed enhanced levels of C18:2n6 in the fatty acid composition of their meat (Aurousseau et al., 2007; Scerra et al., 2011). However, in our work, the lambs with longer grazing time allowances displayed relatively higher C18:2n6c levels, which was the most abundant PUFA. Our observation may be because of the lower proportion of $\mathrm{C} 18: 2 n 6$ in the concentrate. Because the herbages contained higher levels of $\mathrm{C} 18: 3 n 3$ than the concentrates, the lambs under the longer grazing time systems accumulated more $\mathrm{C} 18: 3 n 3$ in their muscle fat, as previously described (Nurnberg et al., 2001). Recently, much attention has focused on $\mathrm{C} 18: 3 n 3$ and its elongation products because $\mathrm{C} 18: 3 n 3$ is associated with a reduced risk of cardiovascular diseases (Roth and Harris, 2010), whereas its elongation products, C20:5n3 and $\mathrm{C} 22: 6 n 3$, have beneficial effects on proper brain and visual development in the fetus and the maintenance of neural and visual tissues throughout life (Ruxton et al., 2004). As expected, we observed higher $\mathrm{C} 20: 5 n 3$ levels in the muscle of the lambs with longer grazing times and less concentrate supplemented since Wood et al. (2008) pointed that conversion of extra $\mathrm{C} 18: 3 \mathrm{n} 3$ into $\mathrm{C} 20: 5 \mathrm{n} 3$ occurred in muscle phospholipid and more $\mathrm{C} 20: 5 \mathrm{n} 3$ deposited due to higher level of $\mathrm{C} 18: 3 \mathrm{n} 3$; this was consistent with other works of Aurousseau et al. (2007).

The CLA is a collective term for different positional and geometric isomers of $\mathrm{C} 18: 2$, which are found in ruminant fats (Guler et al., 2011). The major isomer of CLA is cis-9, trans-11, which represents $80 \%$ to $90 \%$ of the total CLAs, followed by trans-10, cis-12 (Dervishi et al., 2010). Ruminant CLA comes from two sources: one from biohydrogenation in the rumen, and the other from the synthesis of C18:1 trans-11 by the activity of $\Delta 9$-desaturase in animal tissues (Griinari et al., 2000). Because of the beneficial properties in animal models, such as the prevention of carcinogenesis, atherogenesis and obesity, this isomer has received much attention in human research (Nazare et al., 2007; Bassett et al., 2009). Diets rich in forage favor the growth of fibrolytic microorganisms that are principally responsible for the high hydrogenation 
activity in the rumen and consequently of CLA and vaccenic acid (C18:1 trans-11, precursor of CLA in tissue) production (Aurousseau et al., 2007; Daley et al., 2010). In our work, we did not observe that grazing could enhance the occurrence of CLA and its precursor (trans-vaccenic acid) obviously, but we found that levels of both these compounds tended to be higher in the longer grazing-time allowance treatments than in the shorter ones.

The percentages of SFAs and PUFAs are important because of their influence on the healthiness of meat. Although most SFAs are presumed to increase the risk of heart disease, PUFAs and MUFAs are generally regarded as beneficial to human health (Scollan et al., 2005). To summarize the presence of fatty acids in muscles in our study, a longer grazing time did not achieve lower levels of total SFAs although many other studies have reported that grazing could decrease the proportion of total SFAs (Ryan et al., 2007). However, we observed a decline of total SFA in Groups A and B, which included the lambs that enjoyed more pasture intake. Because of the higher proportions of $\mathrm{C} 18: 1 n 9$ in concentrate-based lambs and higher C18:2n6 and $\mathrm{C} 18: 3 n 3$ proportions in pasture-based lambs, which were all determined by their diet compositions, we observed higher total MUFA and PUFA values in the lambs that consumed higher amounts of concentrate and herbages, respectively, which agreed with the results of Ryan et al. (2007). In addition, the total amount of $n-6$ PUFA was significantly altered in the muscle fat among the groups; Groups A and B tended to have more total $n-6$ PUFAs than the groups that received concentrate because of the higher levels of C18:2n6 in the muscle. This outcome differed from Guler et al. (2011), who found that there were no differences of $n-6$ PUFAs in the lambs of the concentrate group and the pasture group, and from Nuernberg et al. (2005a), who reported that the proportion of total $n-6$ fatty acids was lower in the muscle fat of grazing lambs. It has been widely believed that grass feeding can improve the proportion of $n-3$ PUFAs in lamb fat (Aurousseau et al., 2004; Dervishi et al., 2010). In our study, the pure grazing treatment also remarkably increased $n$-3 PUFAs in muscle fat as a result of the higher proportions of $\mathrm{C} 18: 3 n 3$ and C20:5n3. Overall, it can also be deduced that longer grazing times and reduced percentages of concentrate in a lamb's diet can lead to higher $n$-3 PUFA proportions and provide high quality meat for humans because $n-3$ PUFA is known for its protective and modifying effects on a variety of diseases (Nuernberg et al., 2005a) The balance of $n$-3 PUFA and $n-6$ PUFA is another important index used to evaluate the nutritional value of muscle fat (Wood et al., 2004). Williams (2000) noted in his paper that an imbalance in the fatty acid proportion (too much $n-6$ and too little $n-3$ PUFA) existed in the typical western diet, and this could contribute to a greater risk of CHD. It was recommended by the Her
Majesty's Stationery Office (HMSO, 1994) that the proper ratio of $n-3 / n-6$ should be no less than 0.25 . In our study, grazing strategies markedly affected the ratio of $n-3 / n-6$, although both $n-3$ PUFA and $n-6$ PUFA were enhanced by grazing. Additionally, the ratio in the muscle fat of the lambs in Group A was 0.23, which is close to the standard according to the HMSO. In muscle fat, a longer grazing time can improve this ratio, and Group A showed the closest ratio out of the five groups. Similar results were reported by Belo et al. (2009) and Caparra et al. (2007) who found that lambs that grazed in pastures had a higher ratio of $n-3 / n-6$ compared to indoor lambs. Therefore, we can adjust the ratios in lamb meat by extending the duration of grazing or improving the pasture percentage in lamb diets.

\section{CONCLUSION}

Because of their different diet contents, the lambs under different restricted grazing time systems displayed various production performances. In summary, the lambs that grazed for $8 \mathrm{~h} / \mathrm{d}$ or $2 \mathrm{~h} / \mathrm{d}$ on semi-desert areas and received corresponding supplemented concentrate to ensure a similar DM on an everyday basis had enhanced ADG and fat content in their muscle. Likewise, different durations of grazing and supplementary concentrate amounts affected the composition of fatty acids in the lambs' meat. Longerterm grazing and reduced supplementary concentrate in the diets resulted in healthier lamb meat with less harmful SFAs, more $n-3$ PUFAs and higher ratios of $n-3 / n-6$ compared to indoor feeding strategies.

Therefore, increasing the grazing time and moderately decreasing the concentrate in the diets of lambs can be an effective way to provide more and healthy products in the sheep industry. In conclusion, a grazing allowance of $8 \mathrm{~h} / \mathrm{d}$ and proper concentrate (former period of growing season: $150 \mathrm{~g} / \mathrm{d}$, latter: $300 \mathrm{~g} / \mathrm{d}$ ) is recommended based on the results of this study.

\section{ACKNOWLEDGMENTS}

We are grateful to Professor Zoltan Machaty of Purdue University for his valuable suggestions on the manuscript. Great thanks also go to Mr. Li Kechang (Ningxia Hui Nationality Autonomous Region grassland stations) and Mr. Liu Yuhong (Ningxia Hui Nationality Autonomous Region Yanchi County grassland stations) for their help during the study. The authors acknowledge the financial support from the projects of China Agricultural Ministry (200903060 and CARS-39).

\section{REFERENCES}

AOAC. 1995. Official Methods of Analysis. 16th edn. Association 
of Official Analytical Chemists, Washington, DC, USA.

Atti, N. and M. Mahouachi. 2009. Effects of feeding system and nitrogen source on lamb growth, meat characteristics and fatty acid composition. Meat Sci. 81:344-348.

Aurousseau, B., D. Bauchart, E. Calichon, D. Micol, and A. Priolo. 2004. Effect of grass or concentrate feeding systems and rate of growth on triglyceride and phospholipid and their fatty acids in the M. longissimus thoracis of lambs. Meat Sci. 66: 531-541.

Aurousseau, B., D. Bauchart, X. Faure, A. L. Galot, S. Prache, D. Micol, and A. Priolo. 2007. Indoor fattening of lambs raised on pasture. Part 1: Influence of stall finishing duration on lipid classes and fatty acids in the longissimus thoracis muscle. Meat Sci. 76:241-252.

Balk, E. M., A. H. Lichtenstein, M. Chung, B. Kupelnick, P. Chew, and J. Lau. 2006. Effects of omega-3 fatty acids on serum markers of cardiovascular disease risk: A systematic review. Atherosclerosis 189:19-30.

Banni, S., E. Murru, E. Angioni, G. Carta, and M. P. Melis. 2002. Conjugated linoleic acid isomers (CLA): good for everything? Sci. Aliment. 22:371-380.

Bas, P. and P. Morand-Fehr. 2000. Effect of nutritional factors on fatty acid composition of lamb fat deposits. Livest. Prod. Sci. 64:61-79.

Bassett, C. M. C., A. L. Edel, A. F. Patenaude, R. S. McCullough, D. P. Blackwood, P. Y. Chouinard, P. Paquin, B. Lamarche, and G. N. Pierce. 2010. Dietary vaccenic acid has antiatherogenic effects in LDLr(-/-) mice. J. Nutr. 140:18-24.

Belo, A. T., M. S. Pereira, H. Babo, and C. C. Belo. 2009. Meat fatty acids profile of kid goats from Serpentina breed. Options Mediterraneennes Serie A. 91:245-248.

Bonanome, A. and S. M. Grundy. 1988. Effect of dietary stearicacid on plasma-cholesterol and lipoprotein levels. New. Engl. J. Med. 318:1244-1248.

Caparra, P., F. Foti, M. Scerra, C. Cilione, G. Vottari, V. Galofaro, M. C. Sinatra, and V. Scerra. 2007. Influence of feeding system on fatty acid composition of suckling lambs. Options Mediterraneennes Serie A. 74: 95-99.

Carrasco, S., G. Ripoll, A. Sanz, J. Alvarez-Rodriguez, B. Panea, R. Revilla, and M. Joy. 2009. Effect of feeding system on growth and carcass characteristics of Churra Tensina light lambs. Livest. Sci. 121:56-63.

Chaturvedi, O. H., R. Bhatta, A. Santra, A. S. Mishra, and J. S. Mann. 2003. Effect of supplementary feeding of concentrate on nutrient utilization and production performance of ewes grazing on community rangeland during late gestation and early lactation. Asian Australas. J. Anim. 16:983-987.

Chen, Y., H. Luo, X. Liu, Z. Wang, Y. Zhang, K. Liu, L. Jiao, Y. Chang, and Z. Zuo. 2013. Effect of restricted grazing time on the foraging behavior and movement of tan sheep grazed on desert steppe. Asian Australas. J. Anim. Sci. 26:711-715.

Daley, C. A., A. Abbott, P. S. Doyle, G. A. Nader, and S. Larson. 2010. A review of fatty acid profiles and antioxidant content in grass-fed and grain-fed beef. Nutr. J. 9-10.

de Deckere, E. A. M., O. Korver, P. M. Verschuren, and M. B. Katan. 1998. Health aspects of fish and n-3 polyunsaturated fatty acids from plant and marine origin. Eur. J. Clin. Nutr. 52: 749-753.

de Renobales, M., G. Amores, J. Arranz, M. Virto, L. J. R. Barron,
M. A. Bustamante, J. C. R. de Gordoa, A. I. Najera, I. Valdivielso, E. Abilleira, I. B. de Heredia, F. J. PerezElortondo, R. Ruiz, M. Albisu, and N. Mandaluniz. 2012. Parttime grazing improves sheep milk production and its nutritional characteristics. Food Chem. 130:90-96.

del Campo, M., G. Brito, J. M. S. de Lima, D. V. Martins, C. Sanudo, R. S. Julian, P. Hernandez, and F. Montossi. 2008. Effects of feeding strategies including different proportion of pasture and concentrate, on carcass and meat quality traits in Uruguayan steers. Meat Sci. 80:753-760.

Demirel, G., H. Ozpinar, B. Nazli, and O. Keser. 2006. Fatty acids of lamb meat from two breeds fed different forage: Concentrate ratio. Meat Sci. 72:229-235.

Dervishi, E., C. Serrano, M. Joy, M. Serrano, C. Rodellar, and J. H. Calvo. 2010. Effect of the feeding system on the fatty acid composition, expression of the Delta(9)-desaturase, Peroxisome Proliferator-Activated Receptor Alpha, Gamma, and Sterol Regulatory Element Binding Protein 1 genes in the semitendinous muscle of light lambs of the Rasa Aragonesa breed. BMC. Vet. Res. 6:40.

Diaz, M. T., I. Alvarez, J. De la Fuente, C. Sanudo, M. M. Campo, M. A. Oliver, M. F. I. Furnols, F. Montossi, R. San Julian, G. R. Nute, and V. Caneque. 2005. Fatty acid composition of meat from typical lamb production systems of Spain, United Kingdom, Germany and Uruguay. Meat Sci. 71:256-263.

French, P., E. G. O'Riordan, F. J. Monahan, P. J. Caffrey, M. T. Mooney, D. J. Troy, and A. P. Moloney. 2001. The eating duality of meat of steers fed grass and/or concentrates. Meat Sci. 57:379-386.

German, J. B. and C. J. Dillard. 2006. Composition, structure and absorption of milk lipids: A source of energy, fat-soluble nutrients and bioactive molecules. Crit. Rev. Food Sci. 46:5792.

Griinari, J. M., B. A. Corl, S. H. Lacy, P. Y. Chouinard, K. V. V. Nurmela, and D. E. Bauman. 2000. Conjugated linoleic acid is synthesized endogenously in lactating dairy cows by Delta(9)desaturase. J. Nutr. 130:2285-2291.

Guler, G. O., A. Aktumsek, and A. Karabacak. 2011. Effect of feeding regime on fatty acid composition of longissimus dorsi muscle and subcutaneous adipose tissue of Akkaraman lambs. Kafkas. Univ. Vet. Fak. 17:885-892.

HMSO. 1994. Nutritional Aspects of Cardiovascular Disease. 46th rep. on health and social subjects. Department of Health and Society Security, London, UK.

Kempster, A. J., A. Cuthbertson, and G. Harrington. 1982. The relationship between conformation and the yield and distribution of lean meat in the carcasses of british pigs, cattle and sheep: A review. Meat Sci. 6:37-53.

Kennedy, E., J. Curran, B. Mayes, M. McEvoy, J. P. Murphy, and M. O'Donovan. 2011. Restricting dairy cow access time to pasture in early lactation: The effects on milk production, grazing behaviour and dry matter intake. Animal 5:1805-1813.

Kristensen, I., F. Oudshoorn, L. Munksgaard, and K. Soegaard. 2007. Effect of time at pasture combined with restricted indoor feeding on production and behaviour in dairy cows. Animal $1: 439-448$.

Lee, G. J. 1986. Growth and carcass composition of ram and wether lambs fed at 2 levels of nutrition. Aust. J. Exp. Agric. 26:275-278. 
Lin, L., G. Liu, and Y. Zhang. 2006. Study on the n-alkane patterns of five dominant forage species of the typical steppe grassland in Inner Mongolia of China. J. Agric. Sci. 144:159-164.

Mayes, R. W. and H. Dove. 2000. Measurement of dietary nutrient intake in free-ranging mammalian herbivores. Nutr. Res. Rev. 13:107-138.

McClure, K. E., R. W. Vankeuren, and P. G. Althouse. 1994. Performance and carcass characteristics of weaned lambs either grazed on orchardgrass, ryegrass, or alfalfa or fed allconcentrate diets in drylot. J. Anim. Sci. 72: 3230-3237.

Moloney, A. P., M. T. Mooney, J. P. Kerry, and D. J. Troy. 2001. Producing tender and flavorsome beef with enhanced nutritional characteristics. Proc. Nutr. Soc. 60:221-229.

Nazare J. A., A. B. de la Perriere, F. Bonnet, M. Desage, J. Peyrat, C. Maitrepierre, C. Louche-Pelissier, J. Bruzeau, J. Goudable, T. Lassel, H. Vidal, and M. Laville. 2007. Daily intake of conjugated linoleic acid-enriched yoghurts: effects on energy metabolism and adipose tissue gene expression in healthy subjects. Br. J. Nutr. 97:273-280.

Ntambi, J. M. and H. Bene. 2001. Polyunsaturated fatty acid regulation of gene expression. J. Mol. Neurosci. 16:273-278.

Nuernberg, K., D. Dannenberger, G. Nuernberg, K. Ender, J. Voigt, N. D. Scollan, J. D. Wood, G. R. Nute, and R. I. Richardson. 2005b. Effect of a grass-based and a concentrate feeding system on meat quality characteristics and fatty acid composition of longissimus muscle in different cattle breeds. Livest. Prod. Sci. 94:137-147.

Nuernberg, K., A. Fischer, G. Nuernberg, K. Ender, and D. Dannenberger. 2008. Meat quality and fatty acid composition of lipids in muscle and fatty tissue of Skudde lambs fed grass versus concentrate. Small. Rumin. Res. 74:279-283.

Nuernberg, K., G. Nuernberg, K. Ender, D. Dannenberger, W. Schabbel, S. Grumbach, W. Zupp, and H. Steinhart. 2005a. Effect of grass vs. concentrate feeding on the fatty acid profile of different fat depots in lambs. Eur. J. Lipid. Sci. Technol. 107:737-745.

Nurnberg, K., S. Grumbach, W. Zupp, M. Hartung, G. Nurnberg, and K. Ender. 2001. Enhancing of n-3 fatty acids and conjugated fatty acid In lamb meat by keeping on pasture. Fleischwirtschaft 81:120-122.

Perez-Ramirez, E., R. Delagarde, and L. Delaby. 2008. Herbage intake and behavioural adaptation of grazing dairy cows by restricting time at pasture under two feeding regimes. Animal 2:1384-1392.

Petrova, I., V. Banskalieva, and V. Dimov. 1994. Effect of feeding on distribution of fatty acids at sn-2-position in triacylglycerols of different adipose tissues in lambs. Small. Rumin. Res. 13: 263-267.

Rioux, V. and P. Legrand. 2007. Saturated fatty acids: Simple molecular structures with complex cellular functions. Curr. Opin. Clin. Nutr. Metab. Care 10:752-758.

Roth, E. M. and W. S. Harris. 2010. Fish oil for primary and secondary prevention of coronary heart disease. Curr. Atheroscler. Rep. 12:66-72.

Ruxton, C. H. S., S. C. Reed, M. J. A. Simpson, and K. J. Millington. 2004. The health benefits of omega-3 polyunsaturated fatty acids: A review of the evidence. J. Hum. Nutr. Diet. 17:449-459.

Ryan, S. M., J. A. Unruh, M. E. Corrigan, J. S. Drouillard, and M.
Seyfert. 2007. Effects of concentrate level on carcass traits of Boer crossbred goats. Small. Rumin. Res. 73:67-76.

Scerra, M., P. Caparra, F. Foti, V. Galofaro, M. C. Sinatra, and V. Scerra. 2007. Influence of ewe feeding systems on fatty acid composition of suckling lambs. Meat Sci. 76:390-394.

Scerra, M., G. Luciano, P. Caparra, F. Foti, C. Cilione, A. Giorgi, and V. Scerra. 2011. Influence of stall finishing duration of Italian Merino lambs raised on pasture on intramuscular fatty acid composition. Meat Sci. 89:238-242.

Scollan, N. D., I. Richardson, and A. P. Moloney. 2005. Effect of beef systems on meat composition and quality. In: Proceedings of the 18th Annual Langford Food Industry Conference, Bristol, UK. p. 5.

Vansoest P. J., J. B. Robertson, and B. A. Lewis. 1991. Methods for dietary fiber, neutral detergent fiber, and nonstarch polysaccharides in relation to animal nutrition. J. Dairy. Sci. 74:3583-3597.

Velasco, S., V. Ceneque, C. Perez, S. Lauzurica, M. T. Diaz, F. Huidobro, C. Manzanares, and J. Gonzalez. 2001. Fatty acid composition of adipose depots of suckling lambs raised under different production systems. Meat Sci. 59:325-333.

Velasco, S., V. Ceneque, S. Lauzurica, C. Perez, and F. Huidobro. 2004. Effect of different feeds on meat quality and fatty acid composition of lambs fattened at pasture. Meat Sci. 66:457465 .

Vermorel, M. 1988. Nutrition energetique (Energy Nutrition). (Eds R. Jarrige et al.), Alimentation des bovins, ovins and caprins. INRA, Paris. pp. 57-74.

Vorster, H. H., J. H. Cummings, and J. C. Jerling. 1997. Diet and haemostatic processes. Nutr. Res. Rev. 10:115-135.

Webb, E. C. 2006. Manipulating beef quality through feeding. S. Afr. J. Anim. Sci. 7:5-15.

Williams, C. M. 2000. Dietary fatty acids and human health. Ann. Zootech. 49:165-180.

Wood, J. D., M. Enser, A. V. Fisher, G. R. Nute, P. R. Sheard, R. I. Richardson, S. I. Hughes, and F. M. Whittington. 2008. Fat deposition, fatty acid composition and meat quality: A review. Meat Sci. 78:343-358.

Wood, J. D., R. I. Richardson, G. R. Nute, A. V. Fisher, M. M. Campo, E. Kasapidou, P. R. Sheard, and M. Enser. 2004. Effects of fatty acids on meat quality: A review. Meat Sci. 66: 21-32.

Wu, D. Y. 2004. Modulation of immune and inflammatory responses by dietary lipids. Curr. Opin. Lipidol. 15:43-47.

Xu, X., H. L. Luo, S. Y. Ge, F. Yuan, Y. J. Zhang, K. Liu, X. X. Jin, and L. Y. Yan. 2011. Effects of time-limited grazing on growth performance and viscera measurement of Sunit lambs. Chin. J. Anim. Sci. 47: 65-68.

Yang, A., T. W. Larsen, S. B. Smith, and R. K. Tume. 1999. Delta(9) desaturase activity in bovine subcutaneous adipose tissue of different fatty acid composition. Lipids 34:971-978.

Zervas, G., I. Hadjigeorgiou, G. Zabeli, K. Koutsotolis, and C. Tziala. 1999. Comparison of a grazing- with an indoor-system of lamb fattening in Greece. Livest. Prod. Sci. 61:245-251.

Zhang, X. Q., H. L. Luo, X. Y. Hou, W. B. Badgery, Y. J. Zhang, and C. Jiang. 2014. Effect of restricted time at pasture and indoor supplementation on ingestive behaviour, dry matter intake and weight gain of growing lambs. Livest. Sci. 167: 137-143. 